\title{
EGFR plays an essential role in lipopolysaccharide (LPS)-induced MUC5AC hypersecretion in human bronchial epithelial cells.
}

\author{
Mei-Juan Liu', ${ }^{1,2}$ Fu-Sheng Gao ${ }^{2 *}$, Yong-Quan Liu ${ }^{2}$, Yuan Liu ${ }^{2}$, Zhao-Zhong Cheng ${ }^{1,3 *}$, Zeng-Yan Gao², \\ Hong-Zhi Ji², Hua-Ping Tang ${ }^{4}$ \\ ${ }^{1}$ Medical College of Qingdao University, Qingdao, PR China \\ ${ }^{2}$ Department of Respiratory Medicine, the Affiliated Hospital of Weifang Medical College, Weifang, PR China \\ ${ }^{3}$ Department of Respiratory Medicine, the Affiliated Hospital of Qingdao University, Qingdao, PR China \\ ${ }^{4}$ Department of Respiratory Medicine, Qingdao Municipal Hospital, Qingdao, PR China
}

\begin{abstract}
Background: Excessive mucus secretion is an important characteristic of airway inflammatory diseases, such as asthma. Lipopolysaccharide (LPS) leads to mucus hypersecretion in asthma, and is associated with airway inflammation and remodeling. It is known little about the role of epidermal growth factor receptor (EGFR) in LPS-induced mucin 5AC (MUC5AC) hypersecretion in human bronchial epithelial cells. We aim to investigate the effects of EGFR in the process of MUC5AC hypersecretion.

Methods: The human bronchial epithelial (16HBE) cells were treated with LPS, and pre-treated with AG1478 (specific inhibitor of EGFR). The expression of MUC5AC and EGFR were detected and compared between the different groups. The expression of MUC5AC protein was measured by enzyme linked immunosorbent assay (ELISA). The expressions of MUC5AC and EGFR were measured by immunohistochemistry, and the protein expression of EGFR was monitored by Western blot. The mRNA expression of MUC5AC and EGFR were detected by reverse transcription-polymerase chain reaction (RT-PCR).

Results and conclusions: LPS could induce the high expression of MUC5AC and EGFR in 16HBE cells, and AG1478 decreased the expression of MUC5AC by inhibiting the expression of EGFR. These results showed that EGFR might play an important role in LPS-induced MUC5AC hypersecretion of airway epithelial cells, and AG1478 decreased MUC5AC secretion through inhibiting the expression of EGFR. AG1478 may be a new therapeutic approach for the airway inflammatory diseases.
\end{abstract}

Keywords: Bronchial epithelial cell, Mucus secretion, Epidermal growth factor receptor, AG1478, Lipopolysaccharide. Accepted on April 20, 2018

\section{Introduction}

Asthma is one of the systemic inflammatory diseases, which is characterized by airway remodeling and airway inflammation, airway smooth muscle cell hyperplasia, mucus hypersecretion. The bronchial epithelial cells are affected firstly during the pathophysiologic process of asthma, which are associated with the airway inflammation, airway hyper-responsiveness, and airway remodeling. Mucus hypersecretion is one of the pathophysiological features of asthma, which can lead to airway obstruction.

A variety of inflammatory mediators, pathogenic microorganisms and their metabolites, cold air, proteases can promote the secretion of mucins, which are the main components of mucus [1,2]. Bacterial infection is one of the main factors which can induce mucus hypersecretion, and result in glandular secretion, airway damage and airway remodeling. LPS is a major component of gram-negative bacteria wall and can increase mucin5AC (MUC5AC) expression in a variety of tissues and cells [3,4]. LPS can damage the airway epithelial cells, destroy the defence barrier of airway and induce MUC5AC hypersecretion.

MUC5AC is the major mucin produced by bronchial epithelial cells. It is regulated by several pathways in different type cells. It has been reported that epidermal growth factor receptor (EGFR) activation plays an important role in regulation of MUC5AC secretion in a variety of cells, such as human intrahepatic biliary epithelial cells, gallbladder epithelial cells and human bronchial epithelial cells [4-6]. EGFR plays an important role in the injury and repair processes of airway epithelial cells. We have found that chronic exposure to Aspergillus famigatus up-regulated the expression MUC5AC and EGFR in asthmatic rats, but whether EGFR activation is involved in MUC5AC hypersecretion in the human bronchial 
epithelial cells needs to be investigated further [7,8]. Based on the above reports, we postulate that EGFR pathway may be involved in the regulation of MUC5AC expression in human bronchial epithelial cells. In this study, human bronchial epithelial (16HBE) cells were cultured in vitro with LPS and AG1478. The expression of MUC5AC and EGFR were examined in the $16 \mathrm{HBE}$ cells.

\section{Materials and Methods}

\section{Cell culture and reagents}

16HBE cells were purchased from Rochen Pharma Co. Ltd., (Shanghai, China). The 16HBE cells were cultured in the RPMI1640 cell culture medium supplemented with $10 \%$ fetal bovine serum (FBS), $100 \mathrm{IU} / \mathrm{mL}$ penicillin, $100 \mu \mathrm{g} / \mathrm{mL}$ streptomycin, at $37^{\circ} \mathrm{C}$ in a $5 \% \mathrm{CO}_{2}$ humidified atmosphere. This study designed 4 groups: 1) Group A (normal control group): the $16 \mathrm{HBE}$ cells were cultured in the serum-free RPMI1640 for $24 \mathrm{~h}$; 2) Group B: The 16HBE cells were treated with $100 \mu \mathrm{g} / \mathrm{mL}$ LPS (Sigma) in serum-free RPMI1640 for $24 \mathrm{~h}$; 3) Group $\mathrm{C}$ : the $16 \mathrm{HBE}$ cells were treated with 5 $\mu \mathrm{mol} / \mathrm{L}$ of AG1478 (Sigma) in serum-free RPMI1640 for $24 \mathrm{~h}$; 4) Group D: The $16 \mathrm{HBE}$ cells were pre-treated with $5 \mu \mathrm{mol} / \mathrm{L}$ AG1478 for $10 \mathrm{~min}$ and then treated with $100 \mu \mathrm{g} / \mathrm{mL}$ of LPS in serum-free RPMI1640 for $24 \mathrm{~h}$. After the intervention by LPS and AG1478, the expression of MUC5AC and EGFR were measured in each group cells.

\section{Detection of MUC5AC in the cell culture supernatant}

After $24 \mathrm{~h}$, the cell culture supernatant were collected at different time points $(6 \mathrm{~h}, 12 \mathrm{~h}, 24 \mathrm{~h})$, and centrifuged for 20 $\min$ at $1000 \times \mathrm{g}$ at $2-8^{\circ} \mathrm{C}$. The level of MUC5AC in the supernatant was measured by Enzyme-linked Immunosorbent Assay (ELISA) (the sensitivity was $0.188 \mathrm{pg} / \mathrm{ml}$ ) according to the instructions provided by manufactures (Elabscience, Wuhan, China). The optical density (OD) was detected at a wavelength of $450 \mathrm{~nm}$, and the OD value was proportional to the concentration of MUC5AC.

\section{Immunohistochemistry (IHC)}

The expression of MUC5AC and EGFR were detected with IHC according to the instructions of the immunohistochemical kit. The 16HBE cells were fixed with Paraformaldehyde. Antigen retrieval was performed by incubating with the $1 \%$ BSA for $1 \mathrm{~h}$ at $37^{\circ} \mathrm{C}$ in the incubator after the elimination of endogenous peroxidase activity with $3 \%$ hydrogen peroxide for $10 \mathrm{~min}$. The $16 \mathrm{HBE}$ cells were subsequently incubated with monoclonal anti-MUC5AC and anti-EGFR antibody (1:200, purchased from Abcam Co., Shanghai, China) respectively at $4^{\circ} \mathrm{C}$ overnight. The horseradish peroxidase labelled goat antimouse antibody was used as the secondary antibody reagent and then stained by diaminobenzidine (DAB) kit. The antiMUC5AC and anti-EGFR antibody were substituted with PBS buffer as the negative control. The integrated optical density of positive stain in the $16 \mathrm{HBE}$ cells were detected by Image-Pro plus 6.0 Software.

\section{Western-blot}

The $16 \mathrm{HBE}$ cells were lysed in RIPA lysis buffer for $2 \mathrm{~h}$ at ice and centrifuged for $10 \mathrm{~min}$ at $4^{\circ} \mathrm{C}$. After removal of cell debris by centrifugation $(12,000 \mathrm{~g}, 10 \mathrm{~min})$, equal amounts $(40 \mu \mathrm{g})$ of proteins were separated by $10 \%$ SDS-PAGE and transferred onto nitrocellulose membrane. Nonspecific reactivity was blocked in 5\% non-fat milk in TB-ST for $1 \mathrm{~h}$ at room temperature. The membrane was then incubated with monoclonal antibody of mouse anti-EGFR (Santa Cruz) followed by reaction with anti-mouse IgG-HRP antibody. Specific protein bands were photographed and the immunequantification of reactive proteins was performed by ECL chemiluminescence system (Santa Cruz).

\section{Reverse transcription-PCR analysis of MUC5AC mRNA and EGFR mRNA}

Total RNA was extracted with trizol and reverse transcribed. The cDNA synthesis were performed according to the manufacturer's instructions (SYBRGreen PCR kit, TaKaRa, China).The PCR reactions were performed at $94^{\circ} \mathrm{C}$, degeneration for $3 \mathrm{~min}$, followed by 40 amplification cycles at $94^{\circ} \mathrm{C}$ for $20 \mathrm{~s}, 55^{\circ} \mathrm{C}$ for $20 \mathrm{~s}$, and $70^{\circ} \mathrm{C}$ for $20 \mathrm{~s}$. GAPDH mRNA was used as an internal control to standardize the RNA input. Primer sequences for target genes in the studies are shown in Table 1. Relative quantitation of the MUC5AC mRNA and EGFR mRNA were obtained by the $2^{-\Delta \Delta C T}$ method.

Table 1. Primer sequences in the study.

\begin{tabular}{lll}
\hline \multirow{2}{*}{ MUC5AC } & \multicolumn{2}{c}{ Sequences } \\
\cline { 2 - 3 } & Forward & 5'-CCACACCAGTCACCAGAAAC-3' \\
\hline \multirow{2}{*}{ EGFR } & Forward & 5'-GGCACGGTGTATAAGGGACT-3' \\
\cline { 2 - 3 } & Reverse & 5'-ATCGAGGATTTCCTTGTTGG-3' \\
\hline \multirow{3}{*}{ GAPDH } & Forward & 5'-TGGTATCGTGGAAGGACTCA-3' \\
\cline { 2 - 3 } & Reverse & 5'-CCAGTAGAGGCAGGGATGAT-3' \\
\hline
\end{tabular}

\section{Statistical analysis}

Measurement data were expressed as mean \pm SEM and analyzed with SPSS 16.0 statistical software. The comparisons between different groups were performed by t-test. Statistical significance was set at $\mathrm{P}<0.05$.

\section{Results}

\section{LPS up-regulated the expression of MUC5AC in $16 \mathrm{HBE}$ cells}

The IHC analysis shown that MUC5AC were expressed in the cytoplasm of human bronchial epithelial cells, and stained brown. LPS induced the significantly increasing expression of MUC5AC than control group cells $(\mathrm{P}<0.05)$, and the 
expression were down-regulated after treatment with AG1478 $(\mathrm{P}<0.05)$. The level of MUC5AC in the cell culture supernatant was also higher than normal control group $(\mathrm{P}<0.05)$. AG1478 decreased the expression of MUC5AC compared with group B. There is no difference between group $\mathrm{A}$ and group $\mathrm{C}$ (Figure 1 and Table 2).

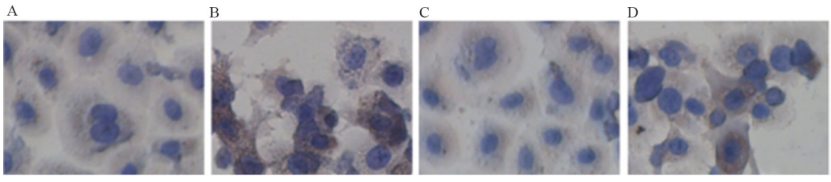

Figure 1. The expression of MUC5AC in 16HBE cells (stained brown): The expression of MUC5AC in group $B$ was enhanced significantly compared with group $A$, and the effect of LPS on MUC5AC hypersecretion was impaired by AG1478 in group $D$. Original magnification, X400.

\section{The expression of MUC5AC mRNA in different groups}

The level of MUC5AC mRNA in the 16HBE cells significantly increased after treating with LPS compared with control group, and AG1478 decreased its higher expression induced by LPS. AG1478 did not decrease the expression of MUC5AC mRNA in group C versus group A (Figure 2).

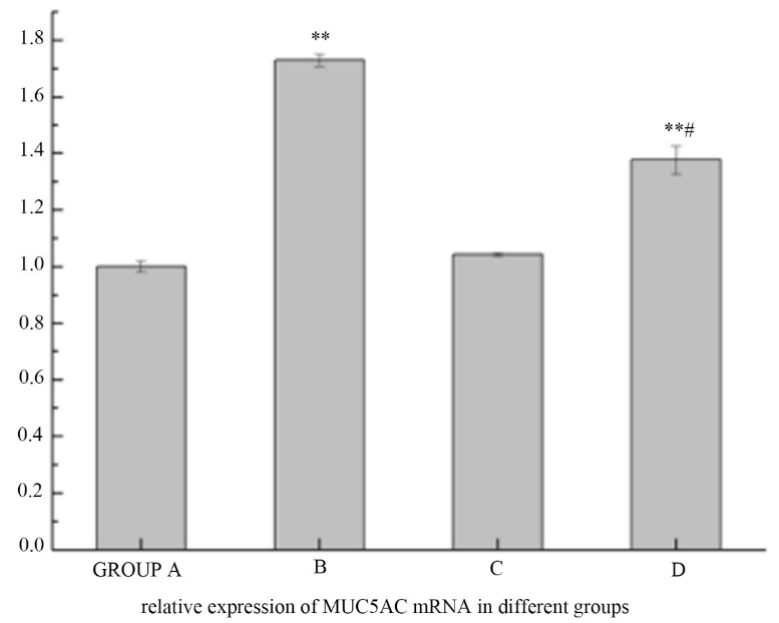

Figure 2. The expression of MUC5AC mRNA levels in each group. Data are expressed as mean $\pm S E M .{ }^{* *} P<0.01$ versus Group $A$, ${ }^{\#} P<0.05$ versus Group B.

\section{LPS increased the expression of EGFR in $16 H B E$ cells}

The western blot analysis revealed that LPS up-regulated the expression of EGFR proteins in the $16 \mathrm{HBE}$ cells, and it could be inhibited by AG1478. The results of IHC also shown that EGFR were activated by LPS in the 16HBE cells, and its effect was inhibited by AG1478 (Figures 3-5).

\section{The expression of EGFR mRNA increased by LPS}

The mRNA level of EGFR increased significantly after intervention with LPS in the $16 \mathrm{HBE}$ cells, and its higher expression could be decreased by AG1478 (Figure 6).
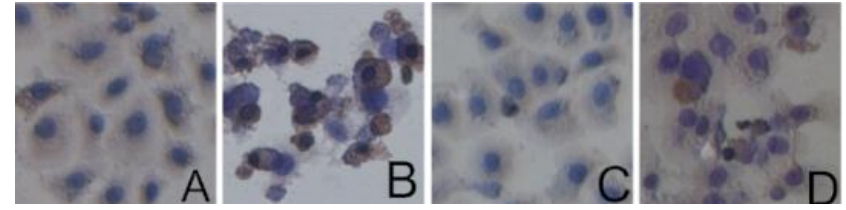

Figure 3. The expression of EGFR in each group $16 H B E$ cells. Imumunohistochemistry-stained $16 \mathrm{HBE}$ cells from different groups showing EGFR higher expression in group $B$ and group $D$ (stained brown); Original magnification, X400.

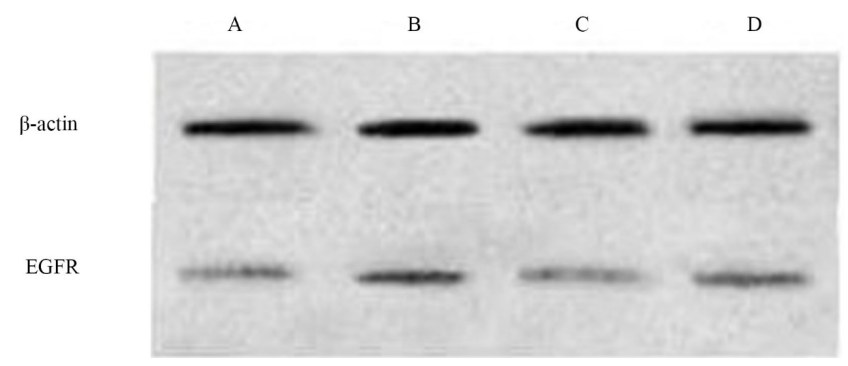

Figure 4. Western-blot detection of EGFR in each group. The expression of EGFR increased significantly in group $B$ and group $D$ versus group $A$. The application of $A G 1478$ inhibited the expression of EGFR in group D versus group $B$.

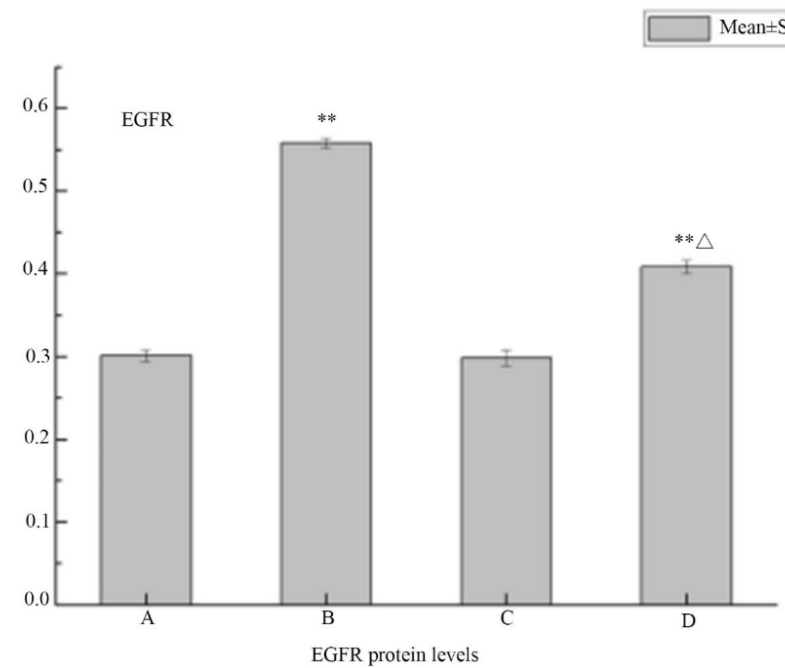

Figure 5. The EGFR protein levels in different groups, Protein levels were measured by EGFR/ $\beta$-actin, ${ }^{* *} P<0.01$ versus Group $A,{ }^{4} P<0.05$ versus Group B.

\section{Discussion}

Mucus is the main defence barrier against the damage factors in the airway. Mucus hypersecretion is an important characteristic of airway inflammatory diseases, such as asthma, chronic obstructive pulmonary disease and cystic fibrosis. MUC5AC is a major component of mucus in airway epithelial cells and regulated by means of an epidermal growth factor receptor (EGFR)-signaling pathway [9]. A variety of inflammatory mediators, pathogenic microorganisms and their metabolites, cold air, proteases can promote the secretion of MUC5AC, and then induce glandular secretion and airway obstruction, which are the main factors of cough and sputum. 
LPS is one of the initiators of inflammation, which is the main component of gram-negative bacteria cell walls. It can result in mucus hypersecretion, airway inflammation and oxidative stress etc. There were many reports that LPS increased the higher expression of MUC5AC in human intrahepatic biliary epithelial cells by up-regulating the expression of EGFR $[3,4,9]$. In the present study, we found that LPS up-regulated the MUC5AC expression in 16HBE cells, and promoted the expression of EGFR at the same time. We speculated that EGFR may play an important role in the process of mucus hypersecretion.

Table 2. The levels of MUC5AC in different groups ( $\mathrm{ng} / \mathrm{ml})$ (ELISA).

\begin{tabular}{llll}
\hline Group & $\mathbf{6} \mathbf{h}$ & $\mathbf{1 2} \mathbf{h}$ & $\mathbf{2 4} \mathbf{h}$ \\
\hline Group A & $19.48 \pm 0.36$ & $18.41 \pm 0.69$ & $19.96 \pm 0.92$ \\
\hline Group B & $31.41 \pm 1.42^{*}$ & $66.78 \pm 2.47^{*}$ & $80.68 \pm 3.19^{*}$ \\
\hline Group C & $17.93 \pm 0.86$ & $18.04 \pm 0.61$ & $18.92 \pm 0.18$ \\
\hline Group D & $26.44 \pm 0.36^{*} \Delta$ & $56.30 \pm 1.17^{*} \Delta$ & $61.96 \pm 0.94^{*} \Delta$
\end{tabular}

Note: ${ }^{*} \mathrm{P}<0.05$ versus group $\mathrm{A}$; ${ }^{\Delta} \mathrm{P}<0.05$ versus group $\mathrm{B}$.

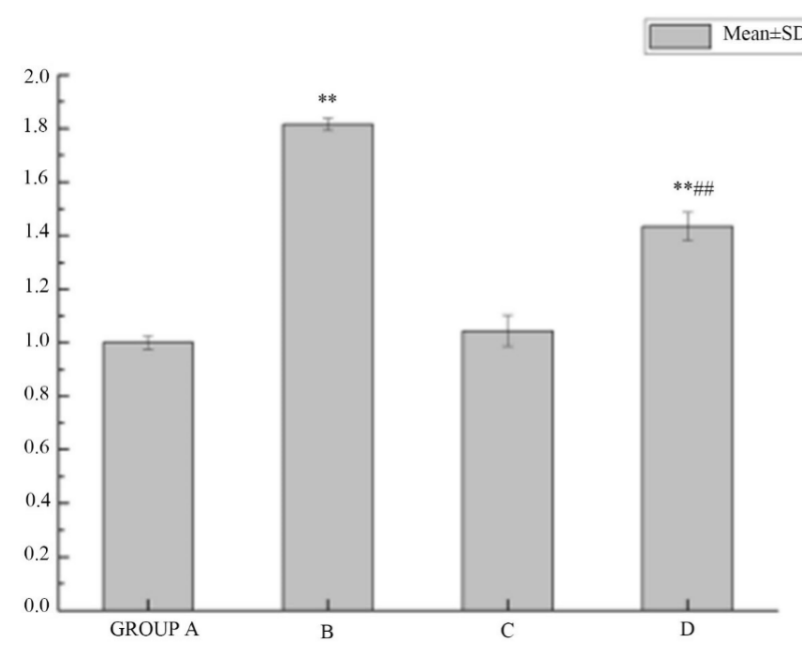

Figure 6. The expression of EGFR $m R N A$ in each group. ${ }^{* *} P<0.01$ versus Group $A,{ }^{\#} P<0.01$ versus Group B.

EGFR is existed in the basal cells, secretory epithelium and interstitial cells of the lung with little expression at normal conditions. It is involved in the regulations of growth and differentiation of the cells. Studies have shown that EGFR expressed highly in some diseases, such as non-small cell lung cancer, asthma and chronic obstructive pulmonary disease. Asthma is a chronic inflammatory disease and involved in a variety of cells and cell components during its pathological process, which resulted in airway remodeling and airway inflammation including goblet cell and airway smooth muscle cell hyperplasia, mucus hypersecretion and so on. EFGR plays an essential role in injury and repair process of the tissue and cells during the pathophysiologic process of asthma. Studies have shown that EGFR was expressed higher in the airway epithelial cells and airway smooth muscle cells in patients with asthma than normal person [10]. The expression intensity of
EGFR was positively correlated with the damage of airway epithelial cells, which may increase hormone resistance in patients with asthma. EGFR can be activated by several potent ligands and increase the MUC5AC expression in different cell types [4,11-16]. We found that LPS could activate EGFR and increase the MUC5AC expression in the 16HBE cells. These studies suggest that high expression of EGFR may be one reason for mucus hypersecretion in airway inflammatory diseases, which is accordance with our results.

AG1478 is one of tyrosinekinase inhibitors, which can inhibit the activity of EGFR tyrosine kinase with high selectivity. Studies have shown that AG1478 inhibited the activity of EGFR through binding the ATP competitively, and then blocked signal pathways mediated by EGFR, which can result in cell apoptosis at a dose-dependent manner [12]. AG1478 significantly inhibited the secretion of MUC5AC and IL-8 of NCI-H292 cells induced by LPS [13]. Shown in a study in vivo, intranasal instillation of AG1478 for an hour could significantly inhibit goblet cell metaplasia, mucus production, and neutrophil infiltration after intranasal LPS instillation in rat nasal epithelium. Our results showed that AG1478 could significantly decrease EFGR expression in the 16HBE cells and inhibit LPS-induced MUC5AC overexpression, indicating EGFR playing an important role in MUC5AC overexpression induced by LPS in the $16 \mathrm{HBE}$ cells. In the present study we found that blocking EGFR can inhibit LPS-induced MUC5AC hypersecretion in the $16 \mathrm{HBE}$ cells, indicating the potential target function of EGFR.

In summary, our results suggested that EGFR play an essential role in LPS-induced mucus hypersecretion and its inhibitor AG1478 could prevent the excessive mucus secretion, and may be used as an effective pharmacotherapy for airway inflammatory diseases, such as asthma.

\section{Declaration of Interest}

The authors report no conflicts of interest. The authors alone are responsible for the content and writing the paper.

\section{References}

1. Kanai K, Koarai A, Shishikura Y, Sugiura H, Ichikawa T, Kikuchi T, Akamatsu K, Hirano T, Nakanishi M, Matsunaga K, Minakata Yand Ichinose M. Cigarette smoke augments MUC5AC production via the TLR3EGFR pathway in airway epithelial cells. Respir Investig 2015; 53: 137-148.

2. Hao Y, Kuang Z, Jing J, Miao J, Mei LY, Lee RJ, Kim S, Choe S, Krause DC, Lau GW. Mycoplasma pneumoniae modulates STAT3-STAT6/EGFR-FOXA2 signaling to induce overexpression of air-way mucins. Infect Immun 2014; 82: 5246-5255.

3. Trussoni CE, Tabibian JH, Splinter PL, O'Hara SP. Lipopolysaccharide (LPS)-induced biliary epithelial cell NRas activation requires epidermal growth factor receptor (EGFR). PLoS One 2015; 10: e0125793. 


\section{epithelial cells}

4. Liu Z, Tian F, Feng X, He Y, Jiang P, Li J, Guo F, Zhao $\mathrm{X}$, Chang H, Wang S. LPS increases MUC5AC by TACE/ TGF- $\alpha$ /EGFR pathway in human intrahepatic biliary epithelial cell. Biomed Res Int 2013; 165715.

5. Hewson CA, Haas JJ, Bartlett NW, Message SD, LazaStanca V, Kebadze T, Caramori G, Zhu J, Edbrooke MR, Stanciu LA, Kon OM, Papi A, Jeffery PK, Edwards MR, Johnston SL. Rhinovirus induced MUC5AC in a human infection model and in vitro via NF- $\mathrm{KB}$ and EGFR pathway. Eur Respir J 2010; 36: 1425-1435.

6. Finzi L, Barbu V, Burgel PR, Mergey M, Kirkwood KS, Wick EC, Scoazec JY, Peschaud F, Paye F, Nadel JA, Housset C. MUC5AC, a gel-forming mucus accumulating in gallstone disease, is overproduced via an epithelial growth factor receptor pathway in the human gallbladder. Am J Pathol 2006; 169: 2031-2041.

7. Gao FS, Gao YY, Liu MJ, Liu YQ. Chronic Aspergillus fumigatus exposure upregulates the expression of mucin $5 \mathrm{AC}$ in the airway of asmatic rats. Exp Lung Res 2012; 38: 256-265.

8. Gao FS, Cao TM, Gao YY, Liu MJ, Liu YQ, Wang Z. Effects of chronic exposure to Aspergillus fumigatus on epidermal growth factor receptor expression in the airway epithelial cells of asthmatic rats. Exp Lung Res 2014; 40: 298-307.

9. Takeyama K, Jung B, Shim JJ, Burgel PR, Dao-Pick T, Ueki IF, Protin U, Kroschel P, Nadel JA. Activation of epidermal growth factor receptors is responsible for mucin synthesis induced by cigarette smoke. Am J Physiol Lung Cell Mol Physiol 2001; 280: L165-L172.

10. Le Cras TD, Acciani TH, Mushaben EM, Kramer EL, Pastura PA, Hardie WD, Korfhagen TR, Sivaprasad U, Ericksen M, Gibson AM, Holtzman MJ, Whitsett JA, Hershey GK. Epithelial EGF receptor signaling mediates airway hyperreactivity and remodeling in a mouse model of chronic asthma. Am J Physiol Lung Cell Mol Physiol 2011; 300: 414-421.

11. Hamilton LM, Torres-Lozano C, Puddicombe SM, Richter A, Kimber I, Dearman RJ, Vrugt B, Aalbers R, Holgate ST, Djukanović R, Wilson SJ, Davies DE. The role of the epidermal growth factor receptor in sustaining neutrophil inflam-mation in severe asthma. Clin Exp Allergy 2003; 33: $233-240$.
12. Ellis AG, Nice EC, Weinstock J, Levitzki A, Burgess AW, Webster LK. High-performance liquid chromatographic analysis of the tyrphostin AG1478, a specific inhibitor of the epidermal growth factor receptor tyrosine kinase, in mouse plasma. J Chromatogr B Biomed Sci Appl 2001; 754: 193-199.

13. Takezawa K, Ogawa T, Shimizu S, Shimizu T. Epidermal growth factor receptor inhibitor AG1478 inhibits mucus hypersecretion in airway epithelium. Am J Rhinol Allergy 2016; 30: 1-6.

14. Nie YC, Wu H, Li PB, Luo YL, Zhang CC, Shen JG, Su WW. Characteristic comparison of three rat models induced by cigarette smoke or combined with LPS: to establish a suitable model for study of airway mucus hypersecretion in chronic obstructive pulmonary disease. Pulm Pharmacol Ther 2012; 25: 349-356.

15. Wang $\mathrm{W}, \mathrm{Xu} \mathrm{X}$, Zheng M, Wan L. Lipopolysaccharides induces MUC-5AC overproduction in human nasal epithelium. Eur Arch Otorhino-laryngol 2013; 270: 541-547.

16. Song L, Tang H, Liu D, Song J, Wu Y, Qu S, Li Y. The chronic and short-term effects of Gefinitib on airway remodeling and inflammation in a mouse model of asthma. Cell Physiol Biochem 2016; 38: 194-206.

\section{*Correspondence to}

Fu-Sheng Gao

Department of Respiratory Medicine

The Affiliated Hospital of Weifang Medical College

Weifang

China

Zhao-Zhong Cheng

Department of Respiratory Medicine

The Affiliated Hospital of Qingdao University

Qingdao

PR China 